\title{
A Compact Dual-Band Metasurface-Based Antenna for Wearable Medical Body-Area Network Devices
}

\author{
Guangchen $\mathrm{Mu}^{1}$ and Pengshan Ren (iD $^{2}$ \\ ${ }^{1}$ Electronic and Information Engineering College, Henan Institute of Technology, Xinxiang, Henan 453000, China \\ ${ }^{2}$ China United Network Communications Group Co. Ltd., Xinxiang Branch, Xinxiang, Henan 453000, China
}

Correspondence should be addressed to Pengshan Ren; pengshan_ren@qq.com

Received 5 March 2020; Revised 24 June 2020; Accepted 8 July 2020; Published 1 August 2020

Academic Editor: Gurvinder S. Virk

Copyright ( $) 2020$ Guangchen $\mathrm{Mu}$ and Pengshan Ren. This is an open access article distributed under the Creative Commons Attribution License, which permits unrestricted use, distribution, and reproduction in any medium, provided the original work is properly cited.

\begin{abstract}
A compact, low-profile wearable antenna capable of operation within the $5.1-5.46 \mathrm{GHz}$ and $5.7-5.85 \mathrm{GHz}$ medical body-area network band is suggested to make the antenna better for wearable devices. The integrated metasurface (MSs) antenna consists of as few as array of three wan-shaped components, directly below the planar waveguide-fed monopole antenna. The measurement of the integrated antenna is $0.56 \lambda_{0} \times 0.56 \lambda_{0} \times 0.08 \lambda_{0}$, all while achieving an average gain of $8.2 \mathrm{dBi}$ in working frequency and a front-to-back ratio (FB) in excess of $19 \mathrm{~dB}$. As demonstrated by in-depth examination, the antenna performs exceptionally well in withstanding the distortion of structure, far superior to planar monopole antenna. Additionally, the metasurface enables the specific absorption rate (SAR) low to $0.84 \mathrm{~W} / \mathrm{kg}$, which makes this type of antenna suited to application in different wearable devices.
\end{abstract}

\section{Introduction}

There is a growing focus on issues like fitness monitor for the old patients with persistent illness, patient tracking and healthcare, and significant increase in Wireless Body-Area Network (WBAN) applications [1-3]. Metamaterials are variety of man-made composite substance, possessing extraordinary characteristics not achievable in a natural state. Metamaterials are expanded by arranging electrically small scatterers into two dimensions, given the name metasurface (MSs) [4]. Metasurfaces have advantages such as low-profile, low loss, easy to design. Attention of relevant research scholars internal and abroad is received. Several important applications are widely used, including polarization control, surface wave couplers, and antenna reflector [5-7].

For the best performance of wearable devices, the antennas used in WBAN require being compact, flexible, lightweight, and preferably comfortable to wear. Initially, some scholars proposed that microstrip antennas and cavity-backed slot antennas are enabled for the purpose of wearing, but failed to display desirable properties with body $[8,9]$. Meanwhile, the inverted-F antenna has been investigated for on-body communications; nevertheless, a considerable amount of energy is absorbed by human tissues because of the inverted-F antenna almost-omnidirectional radiation performance [10]. With the increasing attention paid to MSs, the unique properties of MSs can not only improve the radiation characteristics of the monopole, but also effectively reduce the harm to the human body that is found. Consequently, the metasurfaces are suitable for the wearable antenna systems that people can wear. In 2009, a double-band patch antenna containing (electromagnetic band gap) EBG structures is designed [11]. Structurally, the antenna is comprised of ordinary clothes and works at $2.45 \mathrm{GHz}$ and $5 \mathrm{GHz}$ wireless bands. The EBG structures can increase the positive gain and reduce the coupling between antenna and human body. Subsequently, a flexible dual frequency antenna with MSs is proposed [12]. In order to make the antenna thin and flexible, the substrate is made of polyimide, and thickness of $0.05 \mathrm{~mm}$ significantly lowers the overall size of the antenna. In 2012, a wearable antenna 
with nanosilver ink printed EBG array on photo paper working at the frequency $2.4-2.5 \mathrm{GHz}$ is designed [13]. Afterwards, this design is further optimized [14]. It is only with a $2 \times 1$ array of EBG structures but still working at the ISM band. In 2014, a comfortable dual-band antenna with Artificial Magnetic Conductor (AMC) for WBAN is proposed [15]. The radiation characteristics are improved compared to traditional monopole antennas. In 2016, an antenna with JC structure metasurfaces working in the wireless WLAN band of $5.15-5.25 \mathrm{GHz}$ and $5.72-5.82 \mathrm{GHz}$ is presented [16]. The MSs is isolated of not only the ground but also the main radiator, which greatly reduces the specific absorption rate (SAR). Meanwhile, a wideband antenna with interdigitated MSs is proposed [17]. Finally, the antenna achieves an impedance bandwidth of $10 \%$ and a gain greater than $6.67 \mathrm{dBi}$, and the working principle of the antenna through dispersion analysis is explained. In 2017, a wearable antenna with a novel miniaturized EBG structure at $2.4 \mathrm{GHz}$ is presented [18]. The EBG structure greatly reduces the impact of the antenna due to high loss of the human body and finally results in gain enhancement of $7.8 \mathrm{dBi}$ and SAR reduction of more than $95 \%$. The same year, a MSs antenna for wireless applications is put forward [19]. The MSs improves the bandwidth and gain of patch antennas. Meanwhile, a wireless power transfer (WPT) system integrating with MSs is designed [20]. After integrating with MSs, the efficiency of the WPT system has a great improvement. Compared with the original WPT system, magnetic coupling resonance intensity can be increased by $15.7 \mathrm{~dB}$. In 2018 , a coplanar wave guide fed elastic monopole is proposed [21]. Its bandwidths are $1.5-3.0 \mathrm{GHz}$ and $4.5-6.5 \mathrm{GHz}$. The EBG structure can be used to achieve low SAR. In 2019, a textile antenna integrated with AMC is designed [22]. Compared with the traditional monopole antenna, the proposed integrated antenna has better performance in structural deformation and human body loading.

Herein, a low-profile printed monopole integrated antenna based on a wan-type structure metasurfaces is proposed. The antenna operating frequency band conforms to IEEE802.11a. The integrated antenna proposed in this paper is designed by using the in-phase reflection characteristics of AMC which importantly improves the front-to-back (FB) ratio and accordingly lowers SAR. Furthermore, the designed antenna has the advantages of flexibility and lowprofile which makes it suitable for wearable devices.

Table 1 shows the comparison between the proposed antenna and the work reported in the literature, including antenna volume, bandwidth, gain, and SAR. It can be seen from Table 1 that the antenna designed in the operating frequency band has a relatively high gain. In addition, in order to design antennas suitable for wearable equipment, flexible materials are mainly used as substrate. At present, flexible material technology is difficult to achieve, popularized, or expensive. Therefore, it is important to study how to use conventional substrate materials to design antennas that meet the performance of wearable devices and have a bendable profile.
TABLE 1: Comparison of the proposed integrated antenna with previous works.

\begin{tabular}{lcccc}
\hline Ref. & Volume $\left(\mathrm{mm}^{3}\right)$ & B.W $(\mathrm{GHz})$ & Gain $(\mathrm{dBi})$ & Material \\
\hline$[22]$ & $102 \times 68 \times 3.6$ & $4.3-5.9$ & 6.12 & Pellon \\
{$[19]$} & $38 \times 50 \times 3.048$ & $5.64-5.8$ & 5.8 & RO4350 \\
{$[15]$} & $102 \times 102 \times 3.75$ & $5.71-5.85$ & 8 & Vinyl \\
{$[17]$} & $62.4 \times 33 \times 4.5$ & $3.63-4.23$ & $6.67-7.94$ & RO3003 \\
Proposed & $43.2 \times 43.2 \times 4.6$ & $5.7-5.35$ & & \\
\hline
\end{tabular}

\section{Design of Dual-Band Integrated Antenna}

The integrated MSs antenna involves two components: the top is a planar monopole and the bottom is $3 \times 3$ wan-shaped MSs. The design is shown in Figure 1. The top antenna is fed by coplanar waveguide (CPW) for printing in upper surface of the RO4003 substrate, its relative dielectric constant is 3.38 , loss tangent is 0.0027 , and the thick is $d=0.3 \mathrm{~mm}$, length is $b=32 \mathrm{~mm}$, and width is $a=23.4 \mathrm{~mm}$. The CPW size is $b 3=5.5 \mathrm{~mm}$ and $a 4=11.2 \mathrm{~mm}$. The dimensions are $\mathrm{a} 1=6 \mathrm{~mm}, b 1=18 \mathrm{~mm}$, and $a 3=1.4 \mathrm{~mm}$. The MSs structure is located directly below the monopole antenna and its overall size is $43.2 \times 43.2 \mathrm{~mm}^{2}$. The coupling between the antenna and the MSs can be regulated through adjusting the clearance among the two structures and finally adjusting the interval $d 1=4 \mathrm{~mm}$. The MSs is composed of $3 \times 3$ wanshaped cell and is covered with copper at the bottom. Wantype size is $w 1=6.8 \mathrm{~mm}, w 2=13.4 \mathrm{~mm}, w 3=2.9 \mathrm{~mm}$, and $g 1=0.6 \mathrm{~mm}$, and interval in the two-unit cell is $g=1 \mathrm{~mm}$. The geometric layout of the suggested antenna is depicted in Figure 1.

At Step 1 of the layouts, the sizes of the anisotropic MSs are designed. Figure 2(b) is the equivalent circuit of the MSs unit, and its resonance frequency $f$ is [14]

$$
f=\frac{1}{2 \pi \sqrt{\left(L_{s}+L_{d}\right) C_{s}}}
$$

where $L_{s}$ is the equivalent inductance of the patch, $C_{s}$ is the series surface electric capacity resulting from the clearance among the component structures, and $L_{d}$ indicates the equivalent inductance of the substrate and its fully connected ground on the back, largely affected by the dielectric constant and the thick of the substrate. The change of the size will cause the change of the resonant frequency band of the MSs accordingly. Figure 2(a) shows the MSs unit structure model, the unit size is $l_{1}=14.4 \mathrm{~mm}$, and the remaining sizes are given in Figure 1. The wan-type unit is placed in an air box, and the surroundings are, respectively, set as masterslave boundaries to simulate the periodic MSs structure. The upper surface of the air is set as a floquet port, so that the incident wave enters the unit vertically from the upper surface in the negative $\mathrm{z}$ direction. Based on this simulation, the reflection phase result of the periodic structure can be obtained. Therefore, the size is finally determined through HFSS simulation optimization, and the corresponding reflection phase results are shown in Figure 2(c). It can be seen that the frequency band corresponding to the reflection 
phase in the range of $-90 \pm 45^{\circ}$ satisfies the target frequency band of the antenna operation, namely, $5.1-5.46 \mathrm{GHz}$ and $5.7-5.85 \mathrm{GHz}[16]$.

\section{Results and Discussion}

According to the antenna design, $\mathrm{S}_{11}$ can be finally got as shown in Figure 3(a). Moreover, the suggested antenna is processed by PCB process, and the measurement result is also shown in Figure 3(a). It shows that the suggested antenna obtains good impedance in $5.1-5.46 \mathrm{GHz}$ and $5.7-5.85 \mathrm{GHz}$, and the frequency band satisfies IEEE 802.11a. Meanwhile, using the E8362B network analyzer shows that the measurement result at $5.2 \mathrm{GHz}$ has the lowest return loss of $-25 \mathrm{~dB}$ compared with the simulation result, and the operating bandwidth is almost identical. The measurement result at $5.8 \mathrm{GHz}$ has wider operating bandwidth than the simulation result, which is most likely due to error within the manufacturing tolerances and measurement system. The gap $d_{1}$ between the monopole and the MSs is insulated by a thin foam when measuring. Figure 3(b) illustrates the measurement and simulation outcomes of voltage standing wave ratio (VSWR). The VSWR of the antenna is basically less than 1.5 within the operating frequency, which satisfies the requirements of the technical indicators.

The suggested $\mathrm{E}$ - and $\mathrm{H}$-plane gain total radiation patterns are presented in Figure 4. For comparison, the single monopole pattern is illustrated in this diagram as well. Evidently, the monopole has the radiation feature of the dipole in the E-plane and the omnidirectional radiation character shown in the H-plane. Conversely, radiation is noticeably improved with MSs, and integrated antennas have strong directional radiation properties with a half power beamwidth (HPBW) of roughly $65^{\circ}$ and $72^{\circ}$ at $5.2 \mathrm{GHz}, 60^{\circ}$ and $70^{\circ}$ at $5.8 \mathrm{GHz}$ for E- and H-plan separately.

For comprehension of the radiating mechanisation of this integrated MSs antenna, simulation reveals the surface current in Figure 5 at frequency bands of interest $5.2 \mathrm{GHz}$ and $5.8 \mathrm{GHz}$. For the monopole, the surface current concentrated at feeder and patch connections is at all the lower and upper frequency bands. However, the surface current is primarily concentrated on the monopole and wan-shaped MSs below it at $5.2 \mathrm{GHz}$ and $5.8 \mathrm{GHz}$ for the integrated antenna. It shows that when using MSs as the reflector of the antenna, it is still effectual even the two are very close. Meanwhile, the wan-shaped MSs proposed in the paper design acts as the primary radiator. Even more, radiation characteristics of integrated antenna result in a significantly higher FB.

To validate it, the gain and $\mathrm{FB}$ are calculated as shown in Figure 6 . The monopole has a gain of roughly $2 \mathrm{dBi}$ while the integrated MSs antenna has $8.2 \mathrm{dBi}$ and $8.4 \mathrm{dBi}$ at working frequency, as Figure 6(a) illustrates. In comparison, the integrated MSs antenna shows a FB of around $19 \mathrm{~dB}$, as indicated in Figure 6(b). This value is significantly greater compared to the monopole. It implies that only a low amount of energy is radiated into people after being placed on the body [7]. These properties are conducive to reducing the SAR value to the minimum and improving the robustness of antenna to people, which ensures suitability for the purpose of wearing.

In order to protect the human body from harmful radiation, the International Commission on Non-Ionizing Radiation Protection (ICNIRP) has set out relevant regulatory requirements. According to the regulation, the maximum SAR of $10 \mathrm{~g}$ of tissue must not exceed $2 \mathrm{~W} / \mathrm{kg}$. The Federal Communications Commission stipulates that the average SAR of a $1 \mathrm{~g}$ organization must be no greater than $1.6 \mathrm{~W} / \mathrm{kg}$. The equation indicates that the SAR value is associated with the used input power [3]:

$$
\operatorname{SAR}=\frac{\sigma|E|^{2}}{\rho},
$$

where $\sigma$ indicates the electrical conductivity for the tissue in $\mathrm{S} / \mathrm{m}, E$ denotes the electric field in $\mathrm{V} / \mathrm{m}$, and $\rho$ refers to the mass density of the tissue in $\mathrm{kg} / \mathrm{m}^{3}$. As a benchmark, a $100 \mathrm{~mW}$ power accepted is chosen to evaluate the SAR performance of the proposed integrated antenna.

Figure 7 presents the result of SAR values of $1 \mathrm{~g}$ and $10 \mathrm{~g}$ tissues at $5.2 \mathrm{GHz}$ and $5.8 \mathrm{GHz}$ frequencies. Figure 7 (a) represents the SAR value of $1 \mathrm{~g}$ tissue at $5.2 \mathrm{GHz}$, and the maximum value is $1.5 \mathrm{~W} / \mathrm{kg}$; Figure $7(\mathrm{~b})$ shows the result of the SAR value of $1 \mathrm{~g}$ tissue at $5.8 \mathrm{GHz}$, where the maximum value is $1.6 \mathrm{~W} / \mathrm{kg}$. Obviously, the SAR results are in accordance with international regulations for $1 \mathrm{~g}$ of tissue at both frequencies. Figures 7(c) and 7(d) show the SAR of $10 \mathrm{~g}$ tissue at $5.2 \mathrm{GHz}$ and $5.8 \mathrm{GHz}$; the maximum values are $0.84 \mathrm{~W} / \mathrm{kg}$ and $0.56 \mathrm{~W} / \mathrm{kg}$, respectively, clearly also in accordance with international regulations. The above shows that the SAR must be within the safety limits before using the antenna in WBAN.

In many applications, the antenna is anticipated to be subject to bending throughout working. Figures $8(a)$ and 8 (b) illustrate the model when the bending radius $\mathrm{Ra}$ is $40 \mathrm{~mm}$ and $70 \mathrm{~mm}$, separately. Figures $9(\mathrm{a})$ and 9(b) represent the results of $S_{11}$ and gain of the antenna with varying bending $\mathrm{Ra}$, separately. Figure 9(a) demonstrates that the antenna is moved to the blue in lowfrequency stage while $\mathrm{Ra}=40 \mathrm{~mm}$, and there is almost no change in the high-frequency band. While $\mathrm{Ra}=70 \mathrm{~mm}$, the antenna moved to the red at around $5.2 \mathrm{GHz}$, and the high-frequency section remains unchanged broadly. To sum up, even if the antenna is bent, it still operates in the IEEE.802.11a standard frequency channel and fully meets the $20 \mathrm{M}$ bandwidth. For gain, the designed antenna has a gain reduction of about $1 \mathrm{dBi}$ at $5.2 \mathrm{GHz}$ and remains basically unchanged at $5.8 \mathrm{GHz}$ when Ra goes from $70 \mathrm{~mm}$ to $40 \mathrm{~mm}$.

Figure 10 shows the measured $S_{11}$ when the integrated antenna is placed on the human body, and the simulation results are also included for comparison. When placed on the tissues, the working frequency band is $5.17-5.3 \mathrm{GHz}$ and $5.715-5.94 \mathrm{GHz}$. Obviously, the simulation result is slightly different from the measurement, which may be caused by the measurement error and the influence of the human body conductor. 

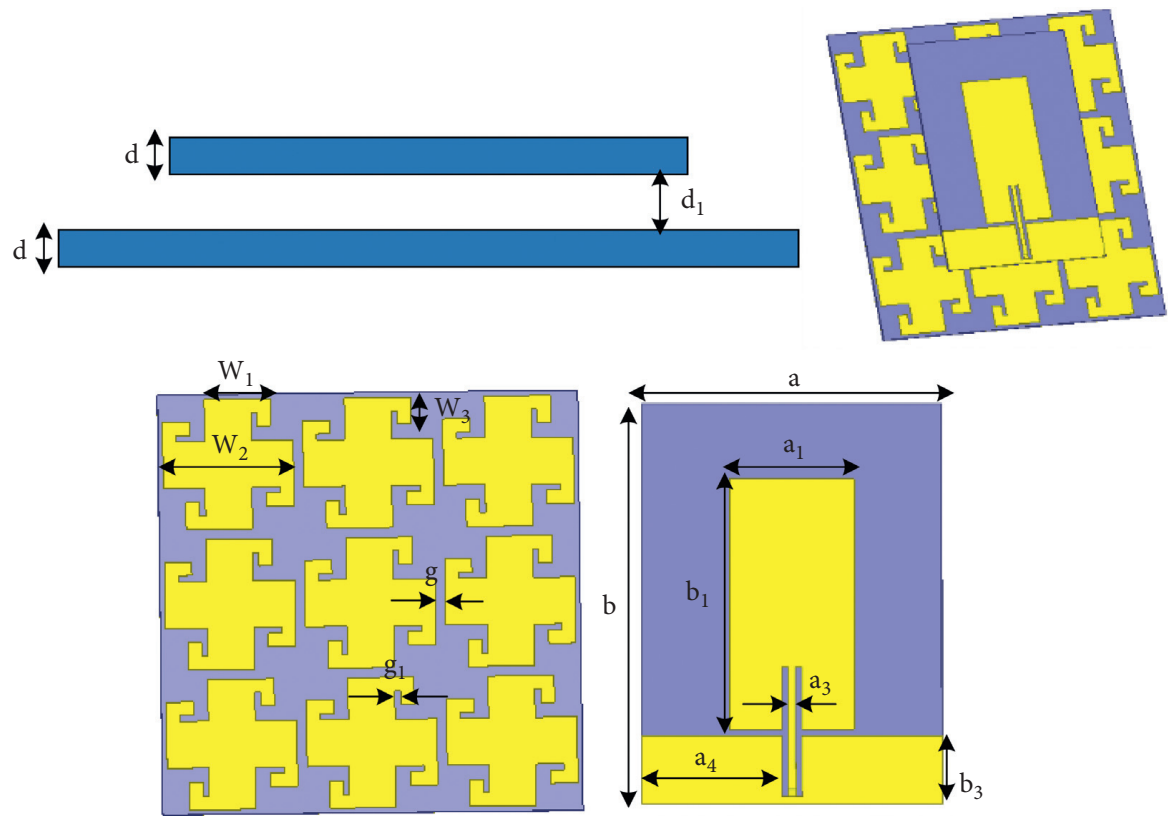

FIGURE 1: Configuration of the integrated planar antenna.

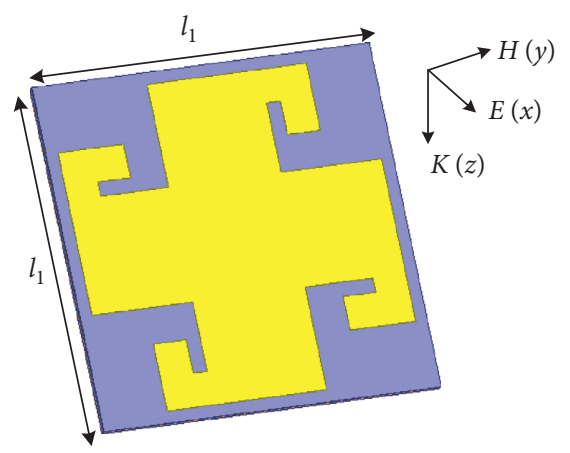

(a)

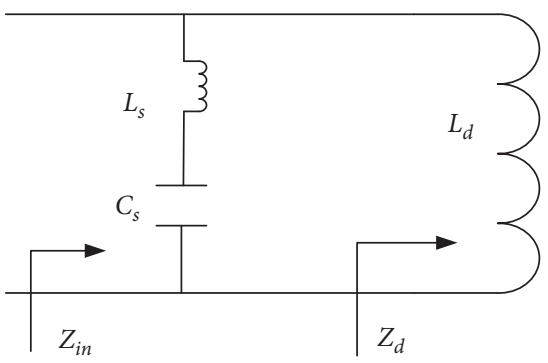

(b)

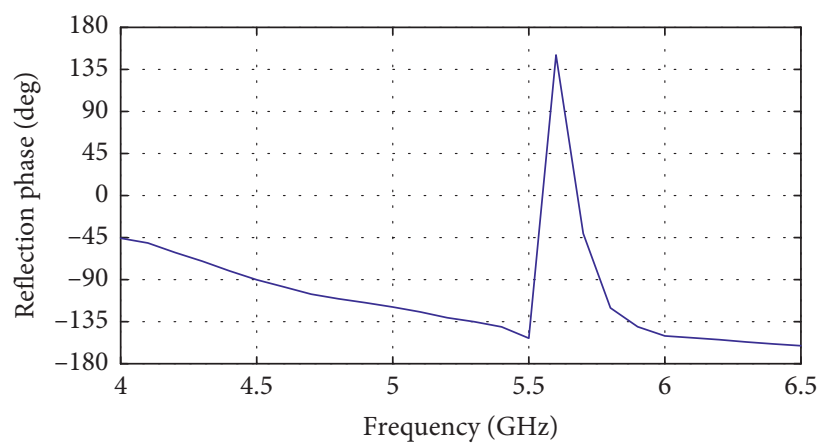

(c)

FiguRE 2: (a) Wan-type metasurface unit structure; (b) equivalent circuit; and (c) reflection phase of unit.

Figure 11 represents the antenna $\mathrm{E}$ - and $\mathrm{H}$-plane gain total radiation pattern at $5.2 \mathrm{GHz}$ and $5.8 \mathrm{GHz}$ in differing circumstances of bending, respectively. The figure reveals that the bending of the integrated MSs antenna is barely impactful on the radiation. It is indicated that the proposed antenna indeed has a little influence on the property caused by bending. 


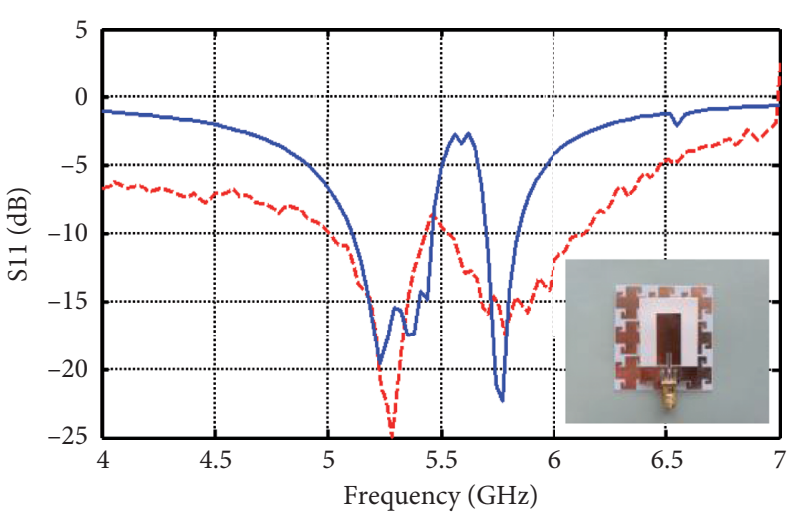

--- Meas. integrated antenna — Simu. integrated antenna

(a)

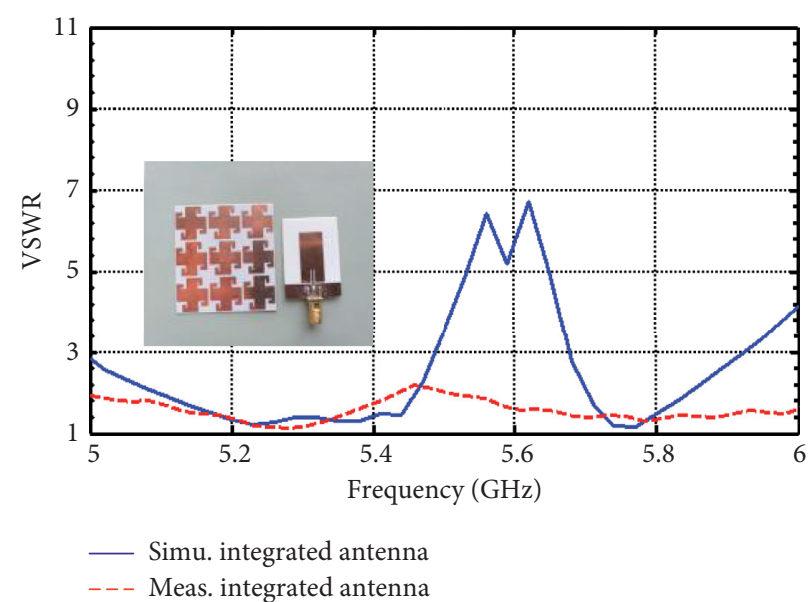

(b)

FIGURE 3: Simulated and measured (a) S11 and (b) VSWR.
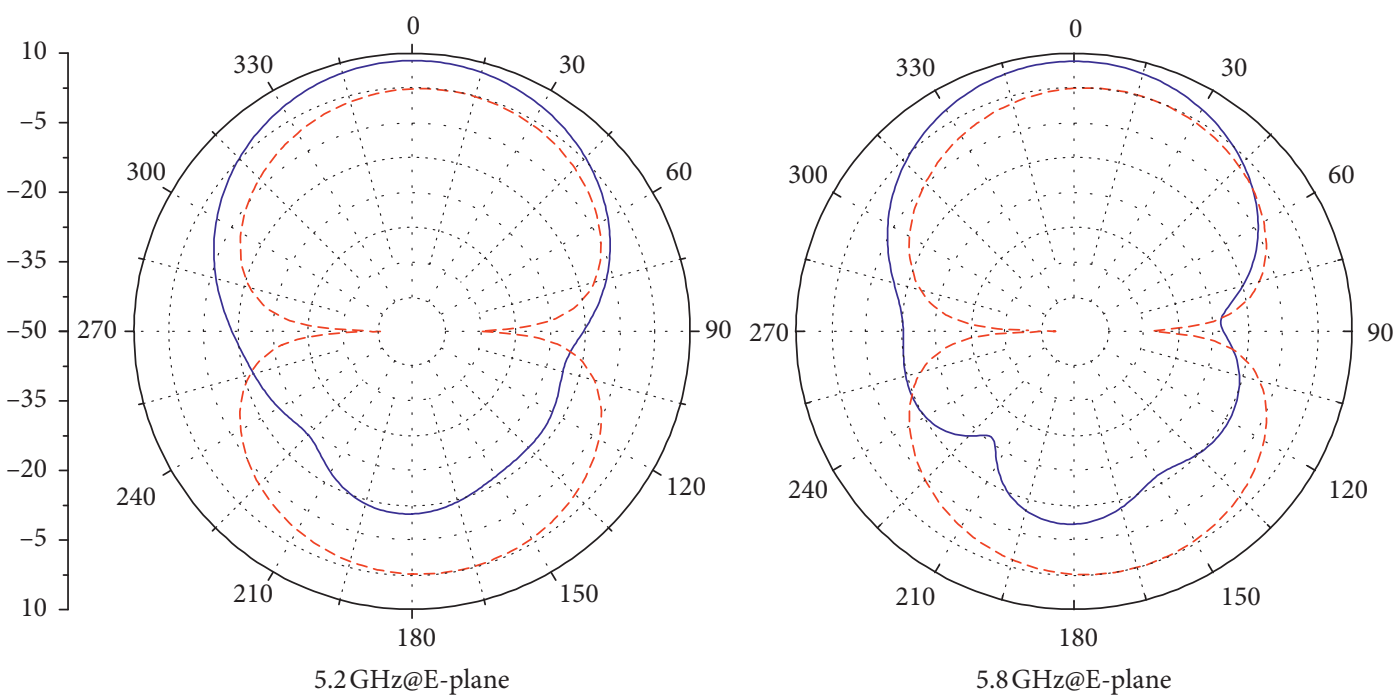

— Integrated antenna

--- Monopole

(a)

Figure 4: Continued. 

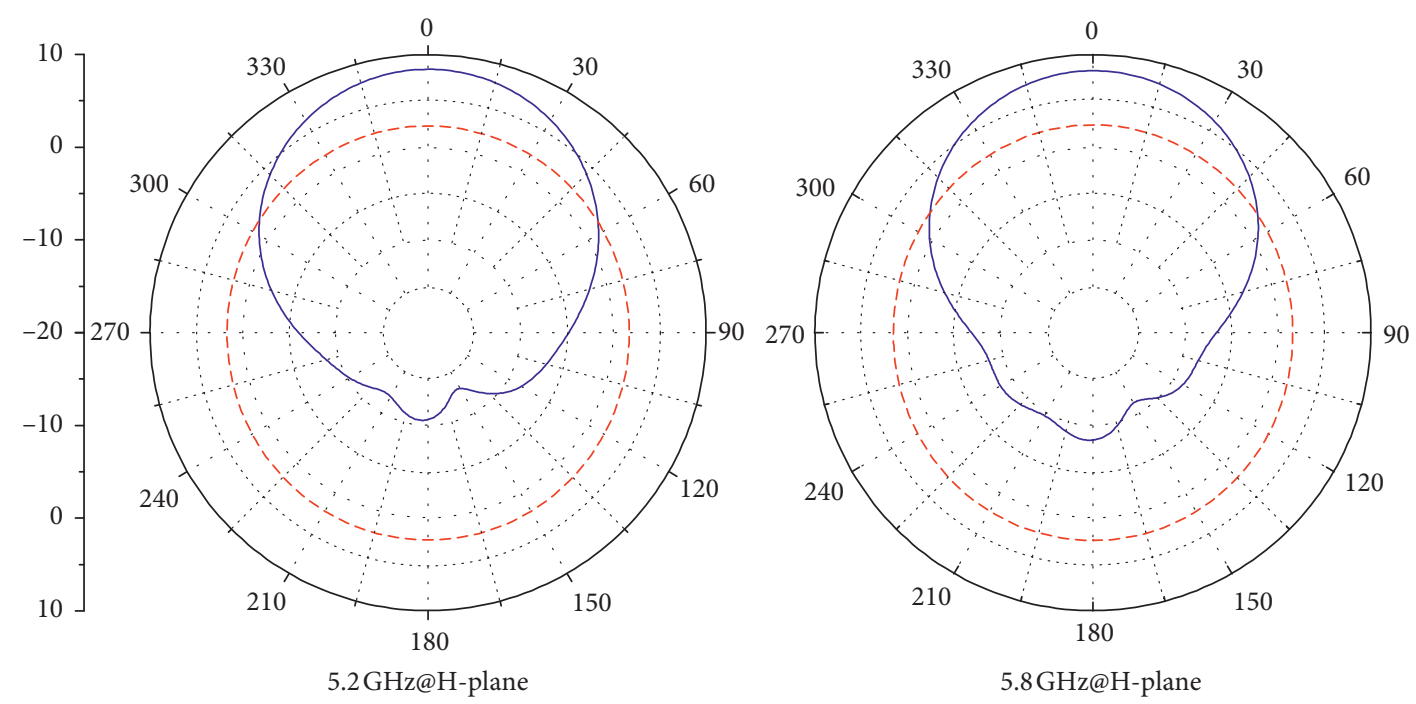

— Integrated antenna

--- Monopole

(b)

FIgURE 4: E- and H-plane gain total radiation patterns at working frequency.
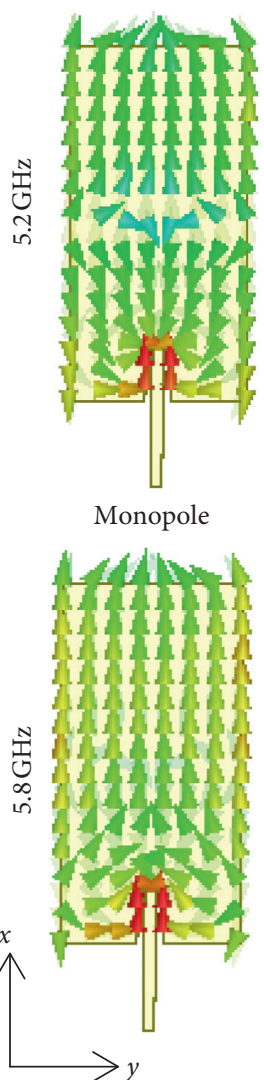

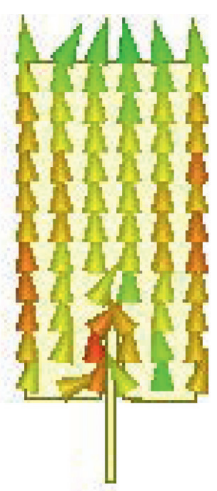

Integrated antenna

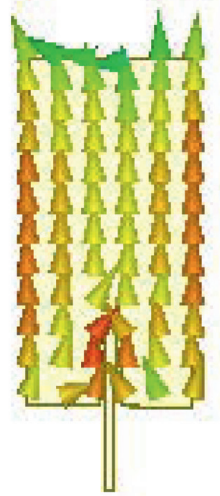

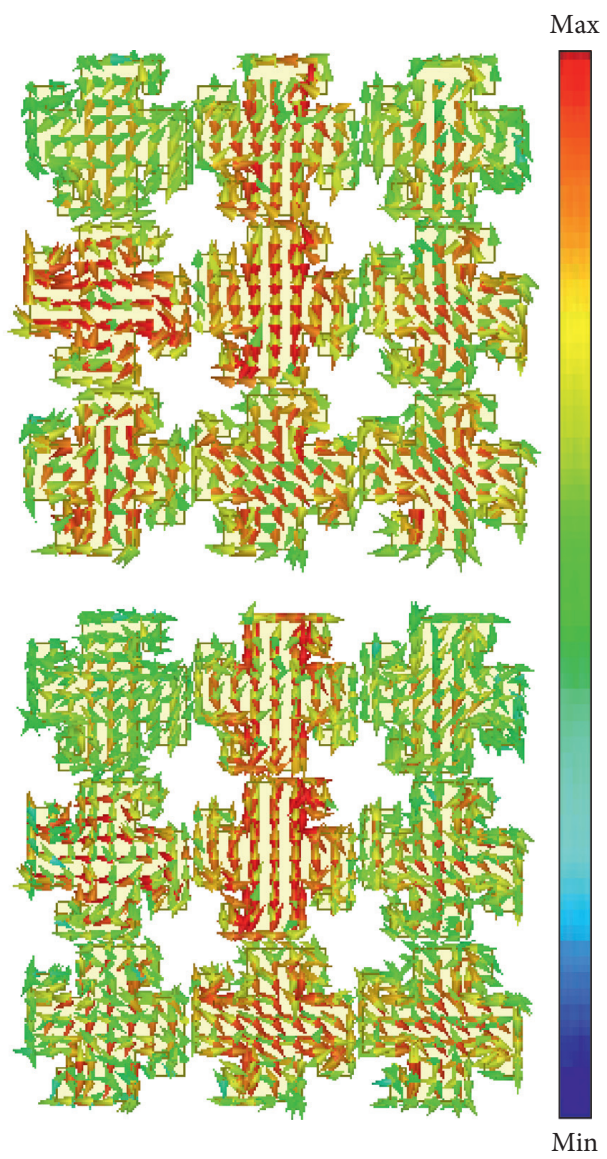

Min

FIgURE 5: Surface current of the monopole and the integrated MSs antenna at working frequency. 


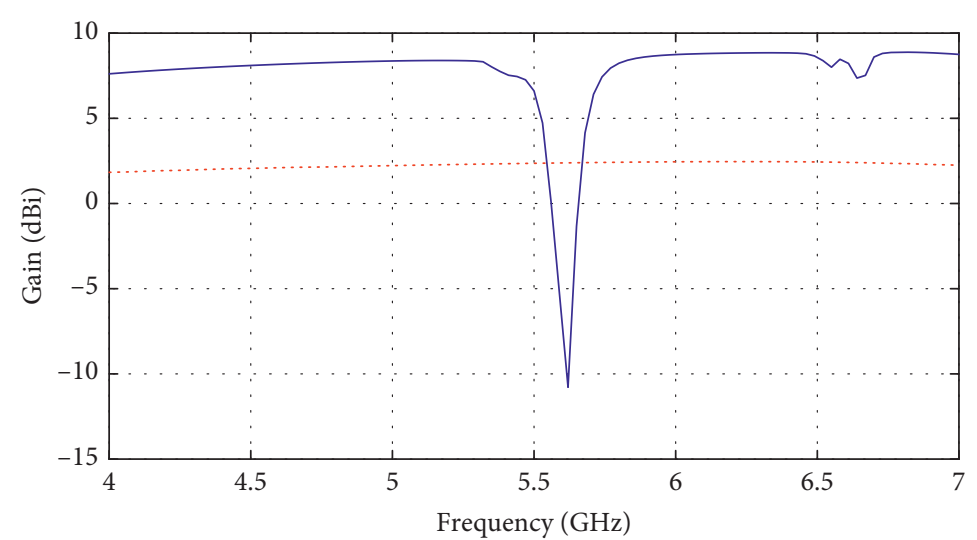

_ Integrated antenna
Monopole

(a)

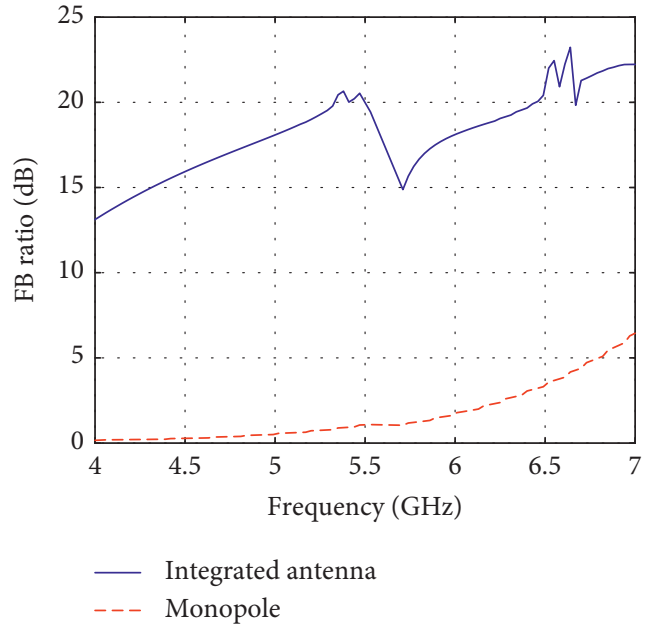

(b)

FIgURE 6: Gain and FB of the monopole and the integrated MSs antenna.

SAR Field $[\mathrm{W} / \mathrm{kg}]$

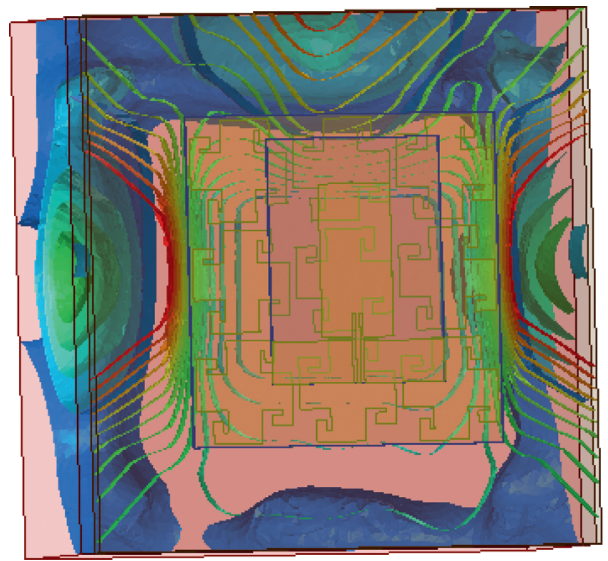

(a)

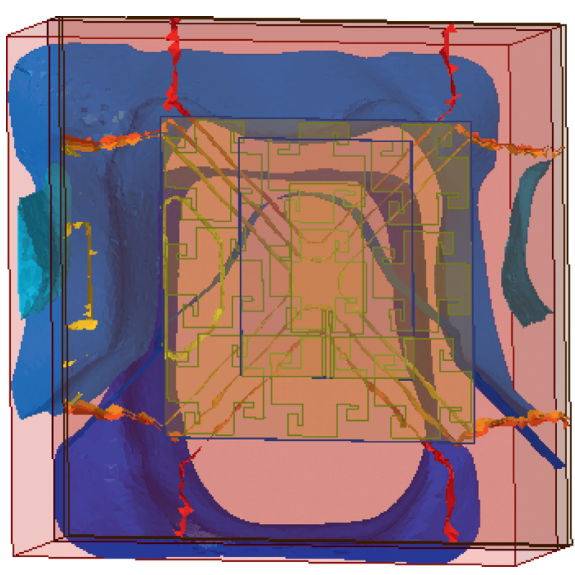

(c)

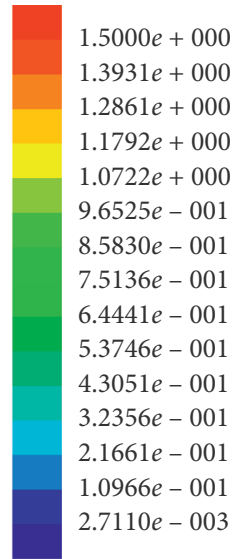

SAR Field $[\mathrm{W} / \mathrm{kg}]$

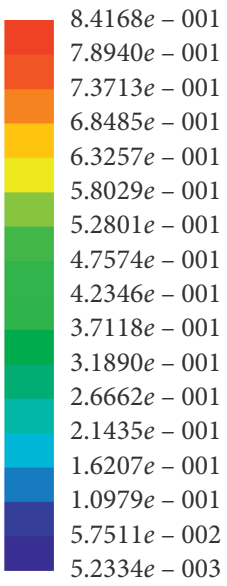

$5.2334 e-003$

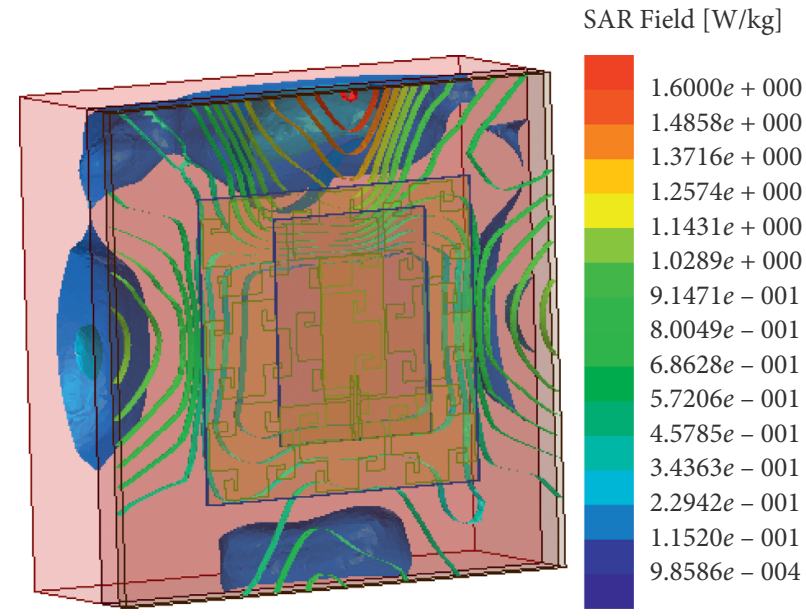

(b)

SAR Field [W/kg]
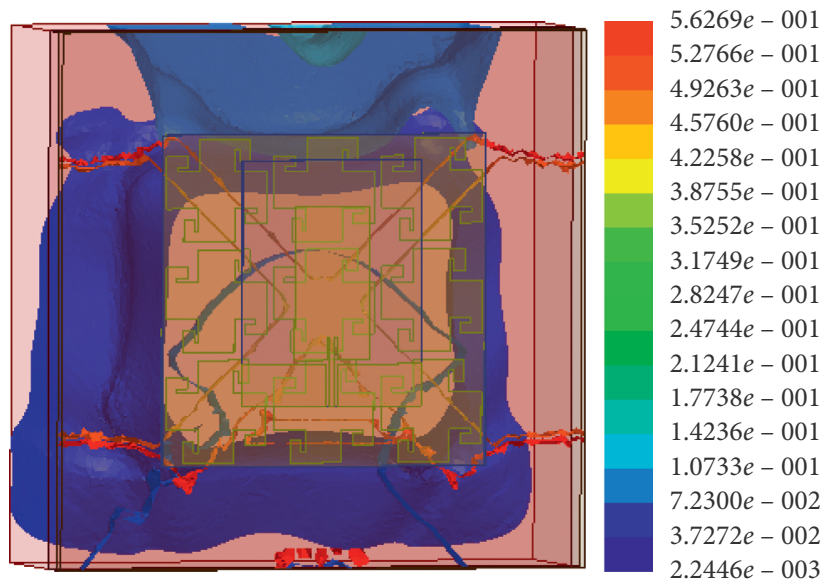

(d)

FIGURE 7: SAR values distribution (a) and (c) at $5.2 \mathrm{GHz}$ and (b) and (d) at $5.8 \mathrm{GHz}$. (a) and (b) $1 \mathrm{~g}$ of tissue. (c) and (d) $10 \mathrm{~g}$ of tissue. 


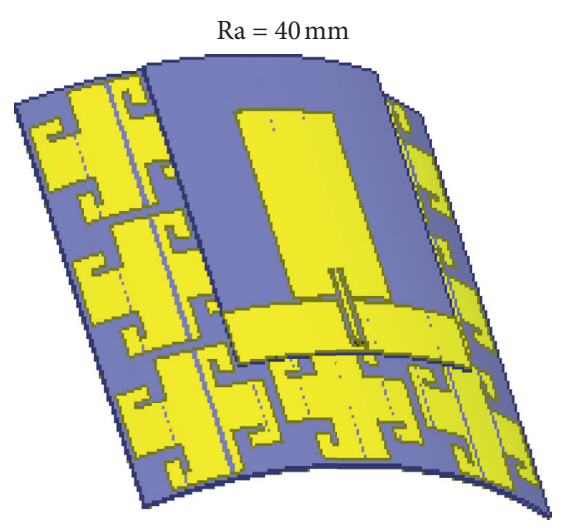

(a)

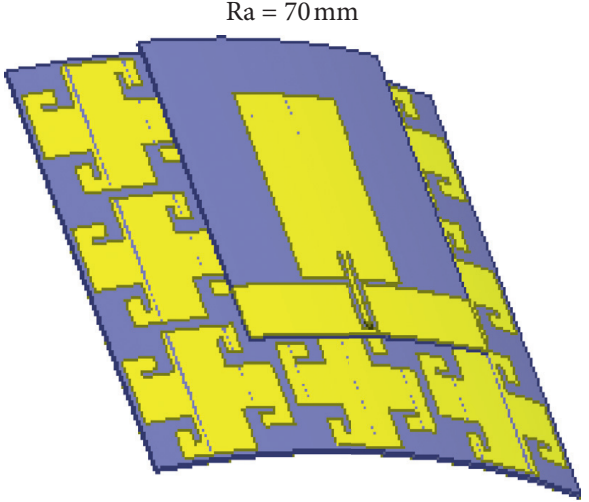

(b)

Figure 8: Structure deformation integrated MSs antenna with varying values of radius: (a) $\mathrm{Ra}=40 \mathrm{~mm}$ and (b) $\mathrm{Ra}=70 \mathrm{~mm}$.

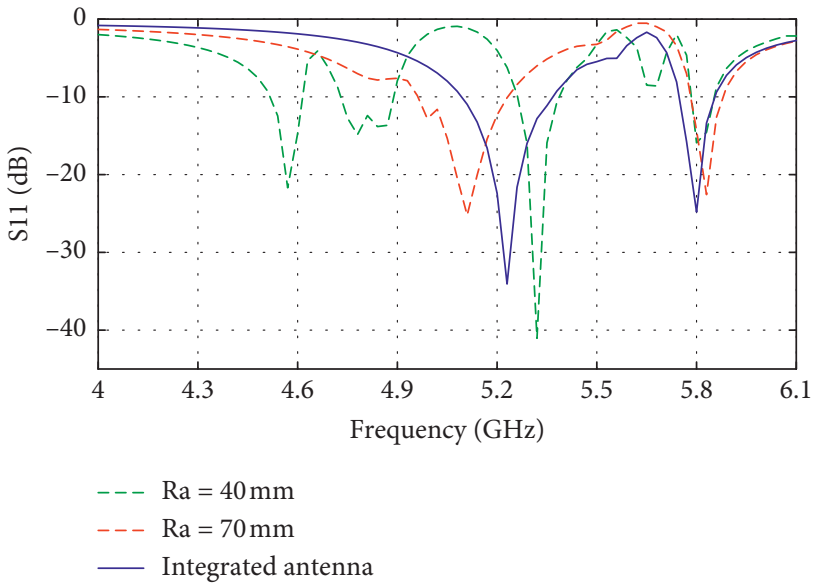

(a)

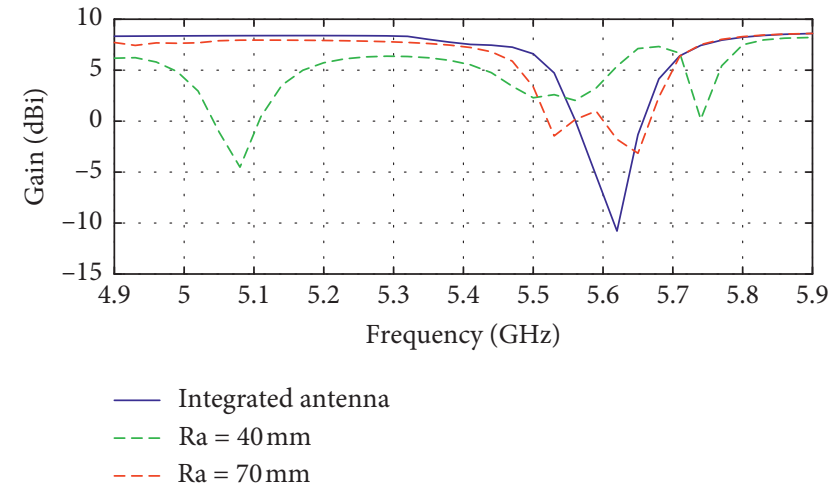

(b)

FIgURE 9: Structure deformation integrated MSs antenna: (a) $S_{11}$ and (b) Gain.

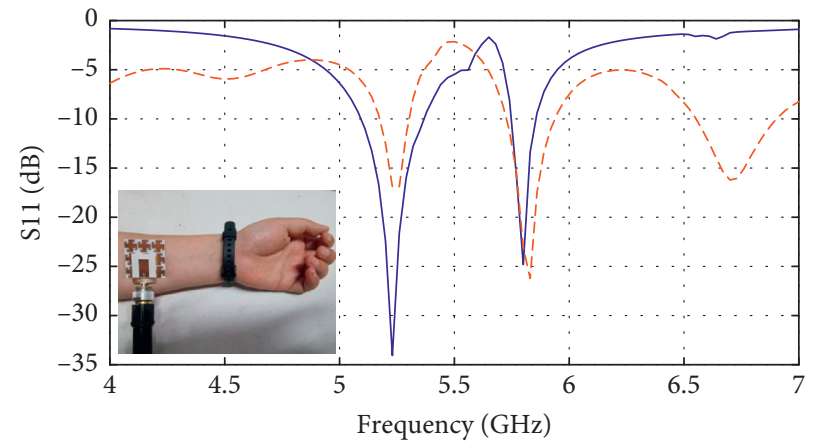

— Simu. integrated antenna
-- Meas. integrated antenna at body

Figure 10: $S_{11}$ of the integrated MSs antenna at human tissues. 


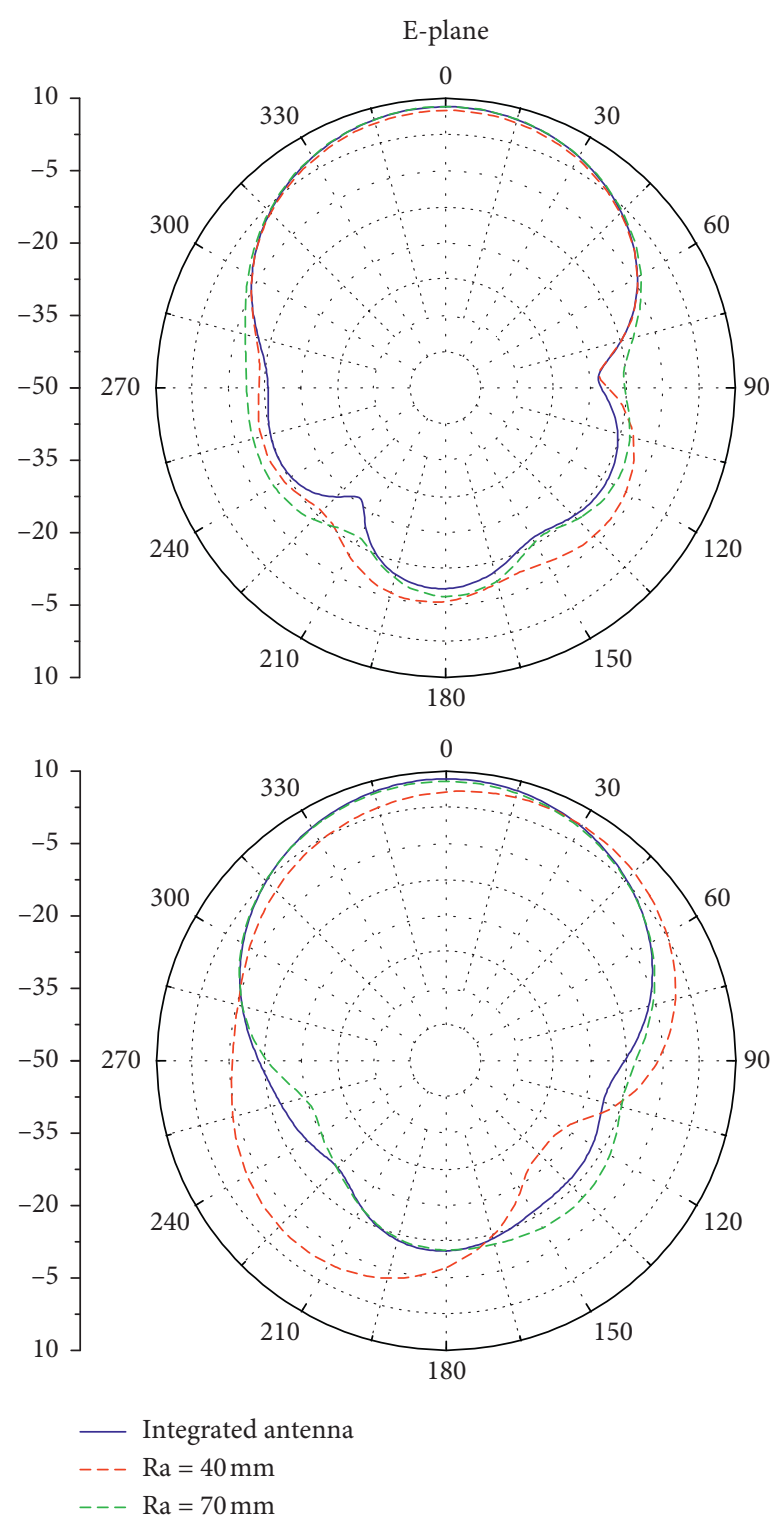

(a)
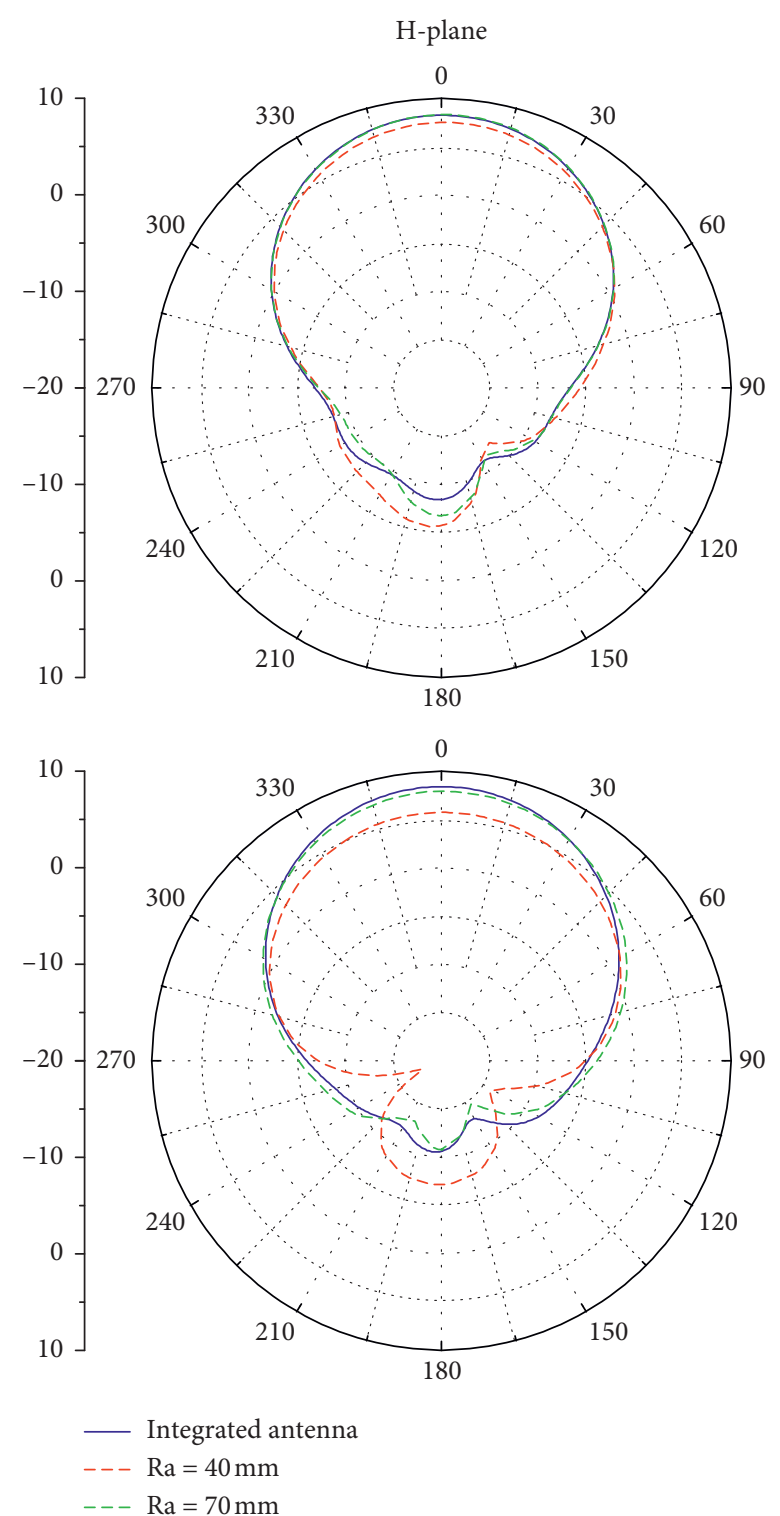

(b)

FIgURE 11: E- and H-plane gain total radiation patterns of structurally deformable wearable antenna: (a) $5.2 \mathrm{GHz}$ and (b) $5.8 \mathrm{GHz}$.

\section{Conclusion}

In the study, a compact, low-profile conformal antenna with a wan-type MSs can be used in WBAN. By optimizing the MSs structure and monopole antenna by HFSS, the impedance bandwidth of $5.1-5.46 \mathrm{GHz}$ and $5.7-5.85 \mathrm{GHz}$ is realized, and the gain is in excess of $8 \mathrm{dBi}$, and due to the fact that the thick of substrate used in the design is only $0.3 \mathrm{~mm}$, the antenna has bendable properties. Meanwhile, a lower SAR and a higher FB of about $18 \mathrm{~dB}$ indicate that massive energy will not be radiated into people when placed near the body. The outcomes of $S_{11}$, gain, and antenna pattern of the integrated MSs antenna after conformation further show the potential of the antenna for WBAN. In addition, the measured results are consistent with the simulation results. In conclusion, the suggested low-profile conformal antenna can become a diamond in the rough for WBAN as far as SAR, bandwidth, radiation direction.

\section{Data Availability}

Only part of the original data are provided in the article.

\section{Conflicts of Interest}

The authors declare that they have no conflicts of interest.

\section{Acknowledgments}

The authors thank the National Natural Science Foundation of China (nos. 61271236 and 61801153) for its support to the research. 


\section{References}

[1] S. Zhu and R. langley, "Dual-band wearable antennas over EBG substrate," Electronics Letters, vol. 43, no. 3, pp. 141-142, 2007.

[2] B. Sakthi and E. Sundarsingh, "EBG backed flexible printed yagi-uda antenna for on-body communication," IEEE Transactions on Antenna \& Propagation, vol. 65, no. 7, pp. 3762-3765, 2017.

[3] H. R. Raad, A. I. Abbosh, H. M. Al-Rizzo, D. G. Rucker et al., "Flexible and compact AMC based antenna for telemedicine applications," IEEE Transactions on Antennas and Propagation, vol. 61, no. 2, pp. 524-531, 2013.

[4] C. L. Holloway, E. F. Kuester, J. A. Gordon, J. O’Hara, J. Booth, and D. R. Smith, "An overview of the theory and applications of metasurfaces: the two-dimensional equivalents of metamaterials," IEEE Antennas and Propagation Magazine, vol. 54, no. 2, pp. 10-35, 2012.

[5] Y. Wang, H. Yang, X. Huang et al., "An X-band parabolic antenna based on gradient metasurface," AIP Advances, vol. 6, no. 7, Article ID 075031, 2016.

[6] Ji Li, M. He, C. Wu et al., "Radiation-pattern-reconfigurable grapheme leaky-wave antenna at terahertz band on dielectric grating structure," IEEE Antenna and Wireless Propagation Letters, vol. 16, pp. 1771-1775, 2017.

[7] Z. H. Jiang, D. E. Brocker, P. E. Sieber, and D. H. Werner, "A compact, low-profile metasurface-enabled antenna for wearable medical body-area network devices," IEEE Transactions on Antennas and Propagation, vol. 62, no. 8, pp. 4021-4030, 2014.

[8] S. Agneessens and H. Rogier, "Compact half diamond dualband textile HMSIW on-body antenna," IEEE Transactions on Antennas and Propagation, vol. 62, no. 5, pp. 2374-2381, 2014.

[9] S. Yun, D.-Y. Kim, and S. Nam, "Folded cavity-backed crossed-slot antenna," IEEE Antennas and Wireless Propagation Letters, vol. 14, pp. 36-39, 2015.

[10] W. El Hajj, C. Person, and J. Wiart, "A novel investigation of a broadband integrated inverted-F antenna design; application for wearable antenna," IEEE Transactions on Antennas and Propagation, vol. 62, no. 7, pp. 3843-3846, Jul. 2014.

[11] S. ZhuR. Langley et al., "Dual-band wearable textile antenna on an EBG substrate," IEEE Transactions on Antennas and Propagation, vol. 57, no. 4, pp. 926-935, 2009.

[12] M. Wang, Z. Yang, J. Wu et al., "Investigation of SAR reduction using flexible antenna with metamaterial structure in wireless body area network," IEEE Transactions on Antennas and Propagation, vol. 66, no. 6, pp. 3076-3086, 2018.

[13] M. M. Tentzeris, Y. J. Ren, and H. Lee, "Monopole antenna with inkjet-printed EBG array on paper substrate for wearable applications," IEEE Antennas and Wireless Propagation Letters, vol. 11, pp. 663-666, 2012.

[14] M. A. B. Abbasi, S. S. Nikolaou, M. A. Antoniades et al., "Compact EBG-backed planar monopole for BAN wearable applications," IEEE Transactions on Antennas \& Propagation, vol. 65, no. 2, pp. 453-463, 2016.

[15] Di Yun-Hui, X.-Y. Liu, M. Manos, and Tentzeris, "A conformable dual-band antenna equipped with amc for wban applications," in Proceedings of the 2014 3rd Asia-Pacific Conference on Antennas and Propagation, IEEE, Harbin, China, July 2014.

[16] H.-L. Yang, B. Xiao, and Y. Yi, "A dual-band low-profile metasurface-enabled wearable antenna for wlan devices," Progress in Electromagnetics Research C, vol. 61, pp. 115-125, 2016.
[17] T. Yue, Z. H. Jiang, and D. Werner, "Compact, wideband Antennas enabled by interdigitated capacitor loaded metasurfaces," IEEE Transactions on Antennas and Propagation, vol. 64, no. 5, pp. 1595-1606, 2016.

[18] A. Y. I. Ashyap, Z. Z. Abidin, S. H. Dahlan et al., "Compact and low-profile textile EBG-based antenna for wearable medical applications," IEEE Antennas and Wireless Propagation Letters, vol. 16, pp. 2550-2553, 2017.

[19] N. Rajak and N. Chattoraj, "A bandwidth enhanced metasurface antenna for wireless applications," Microwave and Optical Technology Letters, vol. 59, no. 10, pp. 2575-2580, 2017.

[20] L. Li, H. Liu, H. Zhang et al., "Efficient wireless power transfer system integrating with metasurface for biological applications," IEEE Transactions on Industrial Electronics, vol. 65, no. 4, pp. 3230-3239, 2017.

[21] A. Anas, Z. Hong-Xing, J. H. Adamu et al., "CPW-fed flexible monopole antenna with $\mathrm{H}$ and two concentric $\mathrm{C}$ slots on textile substrate, backed by EBG for WBAN," International Journal of RF \& Microwave Computer Aided Engineering, vol. 28, no. 7, Article ID e21505, 2018.

[22] S. Alemaryeen and S. Noghanian, "On-body low-profile textile antenna with artificial magnetic conductor," IEEE Transactions on Antennas and Propagation, vol. 67, no. 6, pp. 3649-3656, 2019. 